\title{
IDENTIFYING THE IMPACT OF SOCIAL RESPONSIBILITY ON THE PERFORMANCE OF THE ENTERPRISE
}

GANNA ZHOSAN

https://doi.org/10.35945/gb.2017.04.018

$\mathrm{PhD}$, Candidate of Economic Sciences,

Senior Lecturer, Department of Management and Marketing, Kherson National Technical University, Kherson, Ukraine

\author{
KEYWORDS: SOCIAL RESPONSIBILITY, PRODUCTIVITY DEVELOPMENTS, DEVELOPING PROCESS, \\ ENTERPRISE ACTIVITY, MODELLING
}

\section{INTRODUCTION}

Social responsibility is a value company, affecting the improvement of financial and non-financial indicators of the company. A key benefit of implementing social responsibility programs is to create long-term and medium-term positive reputation in the eyes of members of internal and external business processes.

In the current economic conditions, social responsibility is defined as one of the main factors which determines the performance of the company. Socially responsible enterprise is an integrated system, that creates loyalty and commitment to customers and is attractive for investments, it increases confidence in the company, promotes the commitment of the state and the local community. Thanks to these benefits the company is developing in all areas of activity (economic, environmental, social, legal) and in the medium term may get the opportunity to increase the impact of their activities, hence the relevance of the study. In assessing its activities, it is necessary to consider not only the operational and financial performance, but also the extent of its functioning in the interests of participants in business processes. Public confidence in the enterprise expressed confidence in respect of conformity to the declared values: stability, transparency, integrity, honesty and integrity to all participants of internal and external business processes. This is the basis for the formation of the institute of trust, which is of particular importance in the economic, environmental, social, labor and regulatory balance between the enterprise, shareholders, directors, employees, customers, suppliers, local community, the state. Implementation of the principles of social responsibility in business processes is a factor in the further development of the enterprise and is of paramount importance in solving a number of social problems.

\section{SOCIAL RESPONSIBILITY IN ENSURING PRODUCTIVITY OF THE ENTERPRISE ACTIVITY}

In today's economy more social position affects the reputation and image of the company. Evaluating its activities should be considered not only operational and financial performance, but also how its functioning in the interests of participants in business processes. Confidence in the company expressed confidence in the declared values for compliance, stability, openness, honesty, integrity and respectable attitude to all participants of internal and external business processes. This is the basis for the formation of the institute of trust, which is particularly important in ensuring economic, environmental, social, labor and regulatory balance between the company, shareholders, directors, employees, consumers, suppliers, local community, the state. Implementation of the principles of social responsibility in business processes is a factor in the further development of the company and acquires paramount importance in solving a number of social problems.

The basic idea of social responsibility is that it can contribute to obtaining certain benefits now. Investments in its image and reputation although it does not bring quick profit, but in the future may provide a number of competitive advantages: the growth of the market, increased sales and profits, reduce risk, save operating costs and increase productivity and product quality, staff training, increase customer loyalty. That is, companies that are socially responsible activities can function more effectively. Consequently, improving social responsibility can influence the level of performance improvement activities, taking into account the achievement of economic, environmental, social and legal objectives of the enterprise. Reconciliation of interests of internal and external business processes with enterprise objectives in all areas of activity can enhance the efficiency of socially responsible and productive activity of the enterprise at the same time.

There is a wide variety of concepts of social responsibility of the enterprise, but the basic concept can be considered the duties A. Carroll and the concept of «stakeholders» (stakeholders) [1, 2].

Such a policy of the company provides that the task of the manager is to seek an optimal balance between the different interests of the participants in the internal and external business processes and the interests of the enterprise itself. This concept is called "stakeholders» (stakeholders) and provides that the company is not simply pursuing financial interests, and has a social responsibility.

Social responsibility is inextricably linked to performance of the company because it can not be socially responsible without profit. US researcher Joel Makouer claims «most socially responsible thing most companies can do is to be profitable» [3]. Profit vazhena not only to reward investors, but also to pay fair wages, pay taxes, upgrade equipment, invest in charity, contribute to the prosperity of society in which the company exists. 
There are seven main groups of participants in interna and external business processes, to which the company is responsible: managers, shareholders, employees, customers, suppliers, local community, the state. If the company interacts with them correctly and take into account their interests - it has a high level of social responsibility and correspondingly high productive activities.

Through socially responsible operations, the company sells not only its economic objectives, but also shows the social effects of business activity participants internal and external business processes, which is carried out in conjunction with an activity and satisfies their interests.

\section{THE ESSENCE OF SPLINE INTERPOLATION}

The comprehensive social responsibility indicator and generalizing enterprise activity productivity indicator were being calculated on the previous research stages $[1,2,3,4,5$, $6,7]$. The next research stage is the determination of relation for those indicators and a development the model of their dependence.

The new chapter of the modern mathematics, which calls the theory of splines, has rapidly developed in recent years. Splines allows to effectively solve the problems of experimental dependency processing among the parameters that have enough complex structure [8].

Equally, the rational interpolation and the spline interpolation are one of the polynomial interpolation alternatives.

The basis of the spline interpolation contains the following principle. The interpolation interval is divided into small segments (intervals), on each from which the function is given by the polynomial function of the third degree. The polynomial coefficients are chosen by certain conditions, which are fulfilled (depending on the interpolation method). Common to all types of splines of the third degree requirements are a continuation of this function and passing through the specified points [8]

The main advantages of spline interpolation are its stability and low complexity. Systems of linear equations, which have to solve for the spline constructing, allow obtaining the polynomial coefficients with high accuracy [8]. Because the social responsibility influence of the enterprise activity per- formance is the medium-term, and the spline interpolation of the third degree was being used for determination of their dependence model [9]. This step will allow not only determine a dependence for indicators, but also will establish what the period of time is need that an increasing of the enterprise social responsibility level will influence to the improvement of the performance level of its activity.

For this research, there are two data sets:

$x$ is a set of the most comprehensive social responsibility indicators;

$y$ is a set of the generalizing productivity [10] indicator of enterprise activity;

$t$ is the time period (in this case, there are 2011-2015).

The system $y(x)$ was being proposed, which is described with the help of the following parametric dependencies:

$$
y(x)=\left\{\begin{array}{l}
x=x(t) \\
y=y(t)
\end{array}\right.
$$

The system $\mathrm{y}(\mathrm{x})$ and the influence models were being built with the help of computer mathematical package MapleTM. The program automatically determines the possibility of going through the experimental points. Therefore, the model accuracy rating is not required.

\section{INFLUENCE MODELS BUILDING OF THE SOCIAL RESPONSIBILITY LEVEL ON THE ENTERPRISE PRODUCTIVITY LEVEL}

The individual economic and mathematical influence model of the comprehensive social responsibility indicator to the generalizing enterprise activity productivity indicator for 2011-2015 was being built based on a determination of this system. For example, economic and mathematical influence models in 2013 were presented in the Table 1.

Table 1. Economic and mathematical influence models of the comprehensive social responsibility indicator to the generalizing enterprise activity productivity indicator for 2012-2013.

\begin{tabular}{|c|c|}
\hline Enterprise & Influence Model \\
\hline Enterprise 1 & $y(x)=\left\{\begin{array}{c}x(t)=981,8332-0,4881 t+1,3279(t-2012)^{2}-0,4426(t-2012)^{3} \\
y(t)=-399.6515+0,1988 t+0,0285(t-2012)^{2}-0,0095(t-2012)^{3}\end{array}\right.$ \\
\hline Enterprise 2 & $y(x)=\left\{\begin{array}{l}x(t)=435,5865-0,2162 t+0,0224(t-2012)^{2}-0,0075(t-2012)^{3} \\
y(t)=108,9725-0,0541 t+0,2058(t-2012)^{2}-0,0686(t-2012)^{3}\end{array}\right.$ \\
\hline Enterprise 3 & $y(x)=\left\{\begin{array}{l}x(t)=-97,0971+0,0481 t+0,9474(t-2012)^{2}-0,3158(t-2012)^{3} \\
y(t)=-55,0195+0,0274 t-0,0718(t-2012)^{2}+0,0239(t-2012)^{3}\end{array}\right.$ \\
\hline Enterprise 4 & $y(x)=\left\{\begin{array}{l}x(t)=490,6061-0,2437 t+0,2528(t-2012)^{2}-0,0843(t-2012)^{3} \\
y(t)=337,8827-0,1678 t+0,0417(t-2012)^{2}-0,0139(t-2012)^{3}\end{array}\right.$ \\
\hline Enterprise 5 & $\left\{\begin{array}{c}x(t)=-32.3830+0,0164 t-0,0255(t-2012)^{2}+0,0085(t-2012)^{3} \\
y(t)=-143,3980+0,0714 t-0,4166(t-2012)^{2}+0,1389(t-2012)^{3}\end{array}\right.$ \\
\hline Enterprise 6 & $y(x)=\left\{\begin{array}{l}x(t)=738,2731-0,3666 t-0,7422(t-2012)^{2}+0,2474(t-2012)^{3} \\
y(t)=-33,5968+0,0169 t-0,3862(t-2012)^{2}+0,1287(t-2012)^{3}\end{array}\right.$ \\
\hline
\end{tabular}


The graphical interpretation of the economic and mathematical influence models of the comprehensive enterprise social responsibility indicator of the generalizing enterprise activity productivity indicator in 2011-2015 is shown in Figure 1.

Based on a fact that the reference value for the researched parameters is 1 , then the development dynamics of Enterprise 1 can be called positive (Figure 1a) generally. This model clearly shows the enterprise activity productivity dependence from the social responsibility in the medium term. For example, the comprehensive social responsibility indicator has increased in 2015, but the enterprise activity productivity has increased only in 2014. However, this enterprise could increase its social responsibility in 2015 and this action has led to increasing of the generalizing activity productivity indicator.

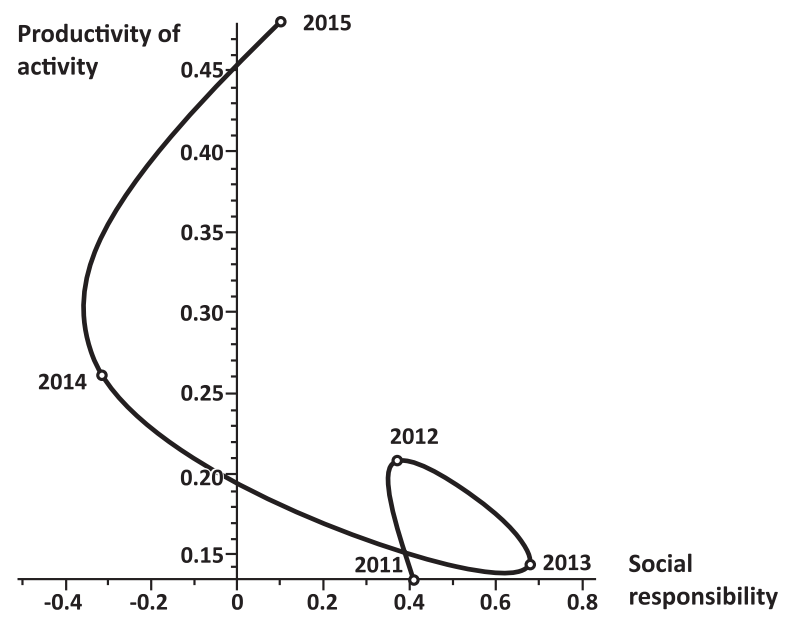

a) community (aimed at the education development, health care, support for culture, arts, sports, non-profit organizations), and others [11, 12, 13, 14].

Every time, expenses to the listed above program have increased after slight increasing of activity productivity. The sharp productivity drop has occurred in the next year. Thus, Enterprise 2 loses the level of enterprise activity productivity not calculating its opportunities.

Enterprise 4 (Figure 2a) has a negative dynamics of a dependence of the generalizing enterprise activity productivity indicator from the comprehensive social responsibility indicator, which steadily declining during researched period. Enterprise management $[12,13,14]$ has not any possibility of funds investing in equipment modernization, staff development, and market research due to shortfall net profit. Through an enterprise management policy, the social responsibility and

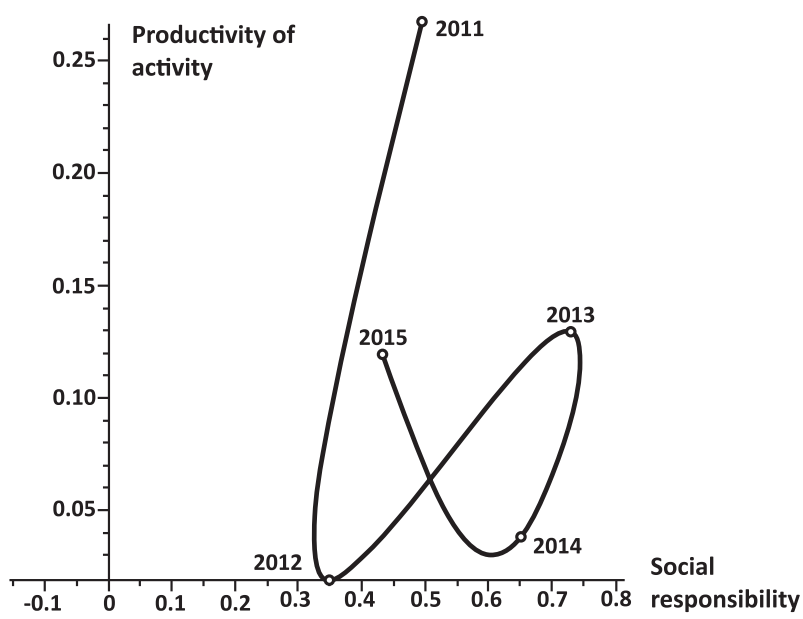

b)

Figure 1. The graphical interpretation of the economic and mathematical influence models of the comprehensive enterprise social responsibility indicator to the generalizing enterprise activity productivity indicator in time: (a) for Enterprise 1, (b) for Enterprise 2 (calculated and built by the authors).

The dynamics model of a dependence of the generalizing activity productivity indicator from the comprehensive social responsibility indicator for Enterprises 2 is not enough stable, as is shown in Figure 4b. In general, the enterprise activity productivity has quite low value, despite on the relatively high social responsibility indicator.

The dependency of the indicators is observed in the medium term. However, the enterprise management rather inefficiently allocates expenses to the following:

Implementing some programs on reducing the energy consumption and energy intensity of production.

Increasing energy efficiency.

Increasing expenses associated with the implementation of some programs to introduce new systems, quality standards, market research expenses, and establish a degree of customer satisfaction by product quality.

Distribution of investments related to the program implementation to support the territory presence and local activity productivity levels are decreasing. Enterprise 4 needs an unpopular anti-crisis measures to get the net profit and, only after this action, we can re-pay attention to the social responsibility and the generalizing enterprise activity productivity indicator is lead to the reference value ' 1 '.

Management of Enterprise 6 is quite irrational, led its policy of social responsibility. After sharply increasing its comprehensive indicator in 2011, the social responsibility indicator level has almost unchanged. This trend has led to productivity level fluctuations, which, after social responsibility level, is increased, then decreased again. If the enterprise's management does not introduce new ways to enhance the social responsibility level, will not revise their policy about resource distribution, and spent money to the social initiatives, then the comprehensive social responsibility indicator can be reduced. Moreover, as a result, the generalizing activity productivity indicator can obtain a significant drop in the medium term, that happened in 2015. 


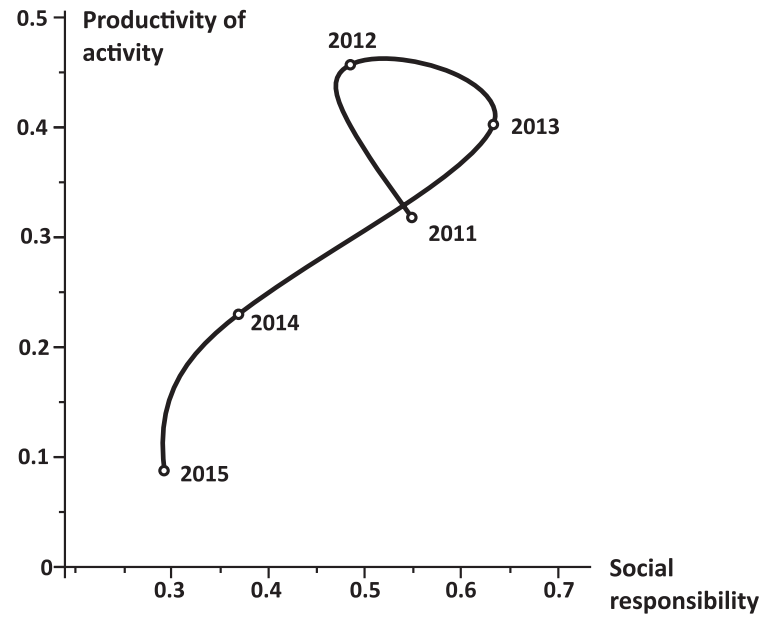

a)

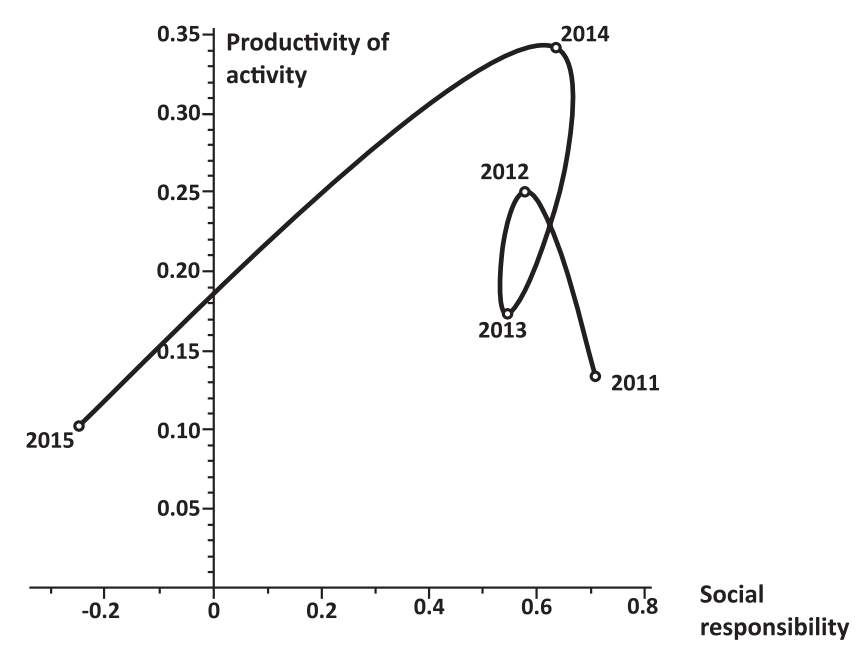

b)

Figure 2. The graphical interpretation of the economic and mathematical influence models of the comprehensive enterprise social responsibility indicator to the generalizing enterprise activity productivity indicator in time: (a) for Enterprise 4; (b) for Enterprise 6 (calculated and built by the authors).

\section{CONCLUSION}

To determine the impact of CSR on the performance of the company developed economic and mathematical model using spline interpolation of the third degree. It is possible to determine the dependence of the parameters and establish exactly what length of time required for this impact. The results suggest that increasing social responsibility contributes in the medium term (1-3 years) increase the level of performance of the company. This is due to growing confidence in the company by members of internal and external business processes.
This trend has led to productivity level fluctuations, which, after social responsibility level, is increased, then decreased again. If the enterprise's management does not introduce new ways to enhance the social responsibility level, will not revise their policy about resource distribution, and spent money to the social initiatives, then the comprehensive social responsibility indicator can be reduced. Moreover, as a result, the generalizing activity productivity indicator can obtain a significant drop in the medium term, which happened in 2015.

\section{REFERENCES:}

1. Zhosan, G.V. Methodical aspects of the definition of the built indicator of social responsibility Enterprise. In Proceedings of the International scientific and practical conference on the state and prospects of development of social responsibility of economic subjects in the modern world, Kyiv, Ukraine, 21-22 November 2013; pp. 15-21. (in Ukrainian)

2. Zhosan, G.V.; Trukhachova, K.V. Conceptual provisions of social responsibility of the enterprise as theoretical basis of the balanced productivity. Natl. Khmelnytsky's Messenger Univ. Econ. Sci. 2013, 2, 247-254. (In Ukrainian)

3. Zhosan, G.V. Calculation of the general indicators of social responsibility of the enterprise for Components. Financial Credit Act. Theory pract. Probl. 2014, 1, 288-300. (In Ukrainian)

4. Korchevska, L.; Zhosan, G.; Kavun, S. Social Responsibility as a Contextual Component of the Enterprise Economic Security. J. Finance Econ. 2013, 1, 95-104, doi:10.12691/jfe-1-4-6. Available online: http://pubs.sciepub.com/jfe/1/4/6/index. html\# (accessed on 10 May 2015).

5. Tarasova, T.F.; Zhosan, A.V.; Bashkatova, V.A. Assessment of social responsibility of the enterprise: criteria and indicators. Bulletin of the Belgorod university of cooperation, economy and right: International scientific-theoretical journal 2014, 2, 120-127. (In Russian)

6. Korchevska, L.A.; Zhosan, G.V. Place of social responsibility in providing economic security of the enterprise [in Ukrainian]. Messenger Transp. Econ. Ind. 2012, 39, 48-52.

7. Zhosan, A.V. Analysis of indexes of social responsibility of the enterprise. In Сборник с доклади от международна научна конференция; Варна - Херсон Украйна - България - Европейски Съюз: съвременно състояние и перспективи, 2013; pp. 48-51. Издательство «Наука и икономика». (In Russian)

8. Grafsky, A.O. Modeling of splines. Manual; Center of Remote Education: Khabarovsk, Russian, 2010. Available online: 
http://edu.dvgups.ru/METDOC/ENF/SAPR/S_KURS_V_GEOM/METOD/ MOD_SPLAYN/MAIN.HTM (accessed on 10 May 2015). (In Russian)

9. Safin, A.I. Methodic of an assessment of social economic efficiency of regional industrial policy. Expert 2009, 14, 32-37. (In Russian)

10. Darmits, R.Z. Communication of productivity and economic efficiency in system of management of the enterprise. Sci. Bull. NLTU Ukr. 2010, 20, 153-161. (In Ukrainian)

11. Miller, L.G. Economics of the Enterprise: Abstract of Lectures: Manual, 2004.

12. Druker, P. Effective Management; HarperCollins: New York, NY, USA, 2004.

13. Fedulova, L.I. Management of the Organizations; Libid: Kiev, Ukraine, 2004. (In Ukrainian)

14. Shershnyova, Z. Strategic Management; KNUE: Kiev, Ukraine, 2004. Available online: http://buklib.net/ component/option,com_jbook/task,view/Itemid,36/catid,184/id,7983 (accessed on 10 May 2015). (In Ukrainian) 


\section{IDENTIFYING THE IMPACT OF SOCIAL RESPONSIBILITY ON THE PERFORMANCE OF THE ENTERPRISE}

GANNA ZHOSAN

https://doi.org/10.35945/gb.2017.04.018

PhD, Candidate of Economic Sciences,

Senior Lecturer, Department of Management and Marketing, Kherson National Technical University, Kherson, Ukraine

KEYWORDS: SOCIAL RESPONSIBILITY, PRODUCTIVITY DEVELOPMENTS, DEVELOPING PROCESS, ENTERPRISE ACTIVITY, MODELLING

\section{SUMMARY}

The impact of the complex index of social responsibility in general indicators proven productivity of the enterprise activity interpolation using spline interpolation of the third degree. This relationship is nonlinear. The economic-mathematical model of the impact of the complex index of social responsibility for synthesis rate productivity of the enterprise activity and is displayed graphically. 